\title{
Kinetic Study on Adsorption of Indigo Carmine Dye Effluents Using Activated Carbon Modified With Metal Chlorides
}

Sivanthaperumal Pillai ${ }^{1 *}$ and Thaminum Ansari ${ }^{1}$

${ }^{1}$ PG and Research Department of Chemistry, Muthurangam Govt. Arts College, Vellore, India

DOI: $10.36348 /$ sjmps.2022.v08i01.005 $\quad$ | Received: 16.11 .2021 | Accepted: 23.12 .2021 | Published: 30.01 .2022

*Corresponding author: Sivanthaperumal Pillai

\section{Abstract}

Heavy metal ions present in the groundwater are toxic pollutants which contaminated of water is a world-wide environmental problem. This paper studies that an attempt made to adsorption kinetics of Indigo carmine dye from dye effluents onto activated carbon modified with metal chlorides is keen interest. The results show that activated carbon modified with metal chlorides such as $\mathrm{FeCl}_{2}, \mathrm{SrCl}_{2}$, and $\mathrm{BaCl}_{2}$ can be used as effective adsorbents for the removal Indigo carmine dye from dye effluents was observed. The kinetics of indigo carmine dye was adsorbed onto activated carbon modified metal chlorides were analyzed using pseudo-first order and pseudo-second order. Results were found to follow pseudo-second order equation.

Keywords: Adsorption kinetics, Indigo carmine dye, effluents, Activated carbon modified with metal chlorides.

Copyright () 2022 The Author(s): This is an open-access article distributed under the terms of the Creative Commons Attribution 4.0 International License (CC BY-NC 4.0) which permits unrestricted use, distribution, and reproduction in any medium for non-commercial use provided the original author and source are credited.

\section{INTRODUCTION}

Textile dyes are structurally different molecules themselves with low or no biodegradability. Dye wastewater from textile and dyestuff industries is difficult to treat. This is because dyes usually have a synthetic origin and complex aromatic structures which make them more stable and more difficult to biodegrade [1]. The presence of dye materials greatly influence the quality of water and the removal of this kind of pollutant is of prime importance. Owing to their complicated chemical structures, dyes are difficult to treat with chemical waste treatment operations. With the increased stringent laws on industrial discharge, it has become very important to treat this wastewater. Because of their detriment and large scale distribution in the ecological environment, their separation and determination has become one of the important studies of environmental analysis.

Removal of dye materials from textile wastewater is necessary or health and environmental protection. For this purpose, conventional methods such as reduction, precipitation, adsorption, coagulation and flocculation, oxidation, ozonation, ion exchange and membrane separation are commonly used. However, among them the adsorption process is the most suitable method because of its high efficiency and economic consideration. However, these methods are not widely used due to their high cost and economic disadvantage. Chemical and electrochemical oxidations, coagulation are generally not feasible on large scale industries. In contrast, an adsorption technique is by far the most versatile and widely used. On the basis of molecular structure, the aromatic complex of the dyes is generally resistant to light, biological activity, oxidizing agent (e.g., ozone), and other degradative environmental conditions.

Adsorption process is also one of the most effective and low cost treatment processes to remove dyes in wastewater. The most common adsorbent materials are alumina silica, metal hydroxides and activated carbon. As proved by many researchers, removal of dyes by activated carbon is economically favorable and technically easier [2]. Commercial Activated carbon is widely used as an adsorbent due to its high adsorption capacity, high surface area, micro porous structure, and high degree of surface respectively [3]. However, commercially available activated carbon is focusing on color removal effective, although expensive or can cause further secondary pollution and might not be economical for waste water treatment [4].

In this study, the activated carbon was modified with metal chlorides such as $\mathrm{FeCl}_{2}, \mathrm{SrCl}_{2}$, and $\mathrm{BaCl}_{2}$ are used to remove the indigo carmine dye in 
Sivanthaperumal Pillai \& Thaminum Ansari., Saudi J Med Pharm Sci, Jan, 2022; 8(1): 27-33

textile dye wastewater by sorption technique [5]. Accordingly, the effects of various parameters on the hybrid process such as $\mathrm{pH}$, initial adsorbent concentration, adsorbent dosage, and contact time are investigated while the response of experiment is the dye removal percentage. The minimal adsorbent concentration and the residual turbidity of the textile waste water are determined by the Jar Test technique [6].

The kinetics of adsorption depends on the adsorbate concentration, the physical and chemical characteristics of the adsorbent. The adsorption kinetics describes the solute uptake rate which in turn governs the residence time at adsorption reaction. It is one of the important characteristics in defining the efficiency of adsorption process [7]. The kinetic experimental data were tested for two kinetics equations, pseudo firstorder and pseudo second-order equations.

\subsection{MATERIALS AND METHODS 3.1. Materials}

All chemicals and reagents were used for synthesis of novel adsorbents were analytical grade and purchased from Merck, India limited and SD fine chemicals and used without any treatment. All glassware (conical flasks, measuring cylinders, beakers, pipettes etc.) were manufactured by Borosil. Indigo carmine dye was purchased from Merck, India. It was used without any improvisation or further purification.

Iron chloride, Strontium chloride, and Barium chloride were used to chemically modify the activated carbon surface. A $500 \mathrm{~mL}$ solution of 500 $\mathrm{mg} / \mathrm{L} \mathrm{FeCl}_{2}, \mathrm{SrCl}_{2}$, and $\mathrm{BaCl}_{2}$ were prepared in separate $500 \mathrm{~mL}$ beaker. Then $10 \mathrm{~g}$ of GAC was added, and the solution was stirred for $3 \mathrm{~h}$. and following filtration of the solution, the coal retained by the filter was dried for $24 \mathrm{~h}$ in an oven at $150{ }^{\circ} \mathrm{C}$.

\subsection{Preparation of Indigo carmine dye and solution}

Stock solution of Indigo carmine dye was prepared by dissolved $50 \mathrm{mg}$ of Indigo caramine dye in $1000 \mathrm{~mL}$ of distilled water to prepare $1000 \mathrm{mg} / \mathrm{L}$ stock solutions. It was stored in a volumetric flask for making other dilute solutions. Samples of different dye concentrations were prepared by dilution of the stock solution. From the stock solutions take $100 \mathrm{~mL}$ indigo carmine dye solution was drained and make up 1000 $\mathrm{mL}$ to get second stock solution of $50 \mathrm{ppm} / \mathrm{L}$. The exact concentration of each indigo carmine dye solution was calculated on mass basis and expressed in terms of $\mathrm{mg} / \mathrm{L}$ of which the adsorption experiments were carried out using nano metal chlorides. Erlenmeyer flask (250 $\mathrm{mL}$ ) fitted with rubber septum were used as the reactors. These solutions were used for constructing calibration curves and for kinetic and equilibrium studies.

\subsection{Batch mode adsorption studies}

Batch mode adsorption studies for Indigo caramine dye were carried out to investigate the effect of different parameters such as $\mathrm{pH}$, adsorbate concentration, adsorbent dose, and agitation time. The effect of adsorbent concentrations $(1.0 \mathrm{~g}-5.0 \mathrm{~g})$ and dye concentrations $(0.5 \mathrm{mg}$ to $5.0 \mathrm{mg} / 100 \mathrm{~mL})(\mathrm{pH}=2$ - 9), contact time (60 min to $300 \mathrm{~min}$ ) on dye removal was investigated. Indigo carmine dye concentration of $500 \mathrm{mg} / 1000 \mathrm{~mL}$, wavelengths was varied and the maximum adsorption was found to be $610 \mathrm{~nm}$. A calibration curve at a characteristic wavelength using different concentrations of indigo carmine dye was measured at different $\mathrm{pHs}$ for adsorption studies. At $\mathrm{pH}$ 6 optimum conditions was derived. Calibration curve is plotted between absorbance and concentration of the dye solution.

\subsection{Batch Sorption experiment with Activated carbon metal chlorides}

The effects of variables including $\mathrm{pH}$, agitation speed, adsorbent dosage, contact time and initial dye concentration on the adsorptive removal of indigo carmine dye on activated carbon modified metal chlorides such as $\mathrm{FeCl}_{2}, \mathrm{SrCl}_{2}$, and $\mathrm{BaCl}_{2}$ were investigated in batch mode. In each experimental run, $50 \mathrm{~mL}$ of Indigo carmine dye solution of different concentrations from $0.5 \mathrm{mg}$ to $5.0 \mathrm{mg} / 100 \mathrm{~mL}$ ) and varying amounts of Activated carbon modified metal chlorides $(0.1 \mathrm{~g}-0.5 \mathrm{~g})$ were kept in a $250 \mathrm{ml}$ erlenmeyer flask. Constant agitation speeds (mechanical orbital shaker incubator) from $100 \mathrm{rpm}$ to $400 \mathrm{rpm}$ at controlled temperature $\left(28+2^{\circ} \mathrm{C}\right)$ was maintained for all the adsorption experiments. The solution $\mathrm{pH}$ was adjusted by addition of dilute aqueous solutions of $\mathrm{HCl}(1 \mathrm{M})$ or $\mathrm{NaOH}(1 \mathrm{M})$ using a $\mathrm{pH}$ meter (EuTech pH meter, Singapore). Samples were taken at different contact times to determine the time required to reach equilibrium. The effect of contact time and adsorbent dose on the sorption capacity of sorbent was studied in the range $60 \mathrm{~min}$ to $300 \mathrm{~min}$ and $0.1 \mathrm{~g}-$ $0.5 \mathrm{~g}$. At the end of the predetermined time, the samples were filtered and stored in a refrigerator and analyzed within 24 hours. Controls were run with only dye without adsorbents and samples collected, prepared, and stored the same way (as samples with adsorbents) for analysis.

Dye concentrations were estimated by UV/Vis spectrophotometer (Shimadzu $800 \mathrm{UV}$ ) at the wavelength corresponding to maximum absorbance, $\lambda_{\max }=610 \mathrm{~nm}$ for indigo dye. After adsorption, the new dyestuff concentration $\mathrm{C}_{\mathrm{e}}(\mathrm{mg} / \mathrm{L})$ was used to calculate the equilibrium dyestuff concentration adsorption $\mathrm{q}_{\mathrm{e}}(\mathrm{mg} / \mathrm{g})$.

The batch process was used so that there is no need for volume correction. The dye concentration retained in the adsorbent phase was calculated according to 
Sivanthaperumal Pillai \& Thaminum Ansari., Saudi J Med Pharm Sci, Jan, 2022; 8(1): 27-33

$q_{\mathrm{e}}=\left(C_{i}-C_{e}\right) V / W$

Where $C_{\mathrm{i}}$ and $C_{\mathrm{e}}$ are the initial and equilibrium concentration $(\mathrm{mg} / \mathrm{L})$ of indigo carmine solution, respectively. $V$ is the volume and $W$ is the weight $(\mathrm{g})$ of the adsorbent.

\subsection{RESULTS AND DISCUSSION}

In this study the kinetic adsorption of metal ions is used to understand the behavior of activated carbon. The pseudo first-order and pseudo second-order models (Eqs. 1 and 2) are employed in this study. An attempt was made to ascertain and utilize newly prepared Activated carbon modified with metal chlorides for textile dye industry waste water treatment methods. The effect of studying different parameters on the adsorption of indigo carmine dye including $\mathrm{pH}$, contact time, and initial adsorbent concentrations were examples of systems investigated and the results are presented.

\section{Adsorption kinetics}

The pseudo first order kinetic model has been widely used to predict dye adsorption kinetics. A linear form of pseudo-first order model was described by Lagergren. The dye adsorption kinetics following the pseudo first order model is given by [8] ;

$\mathrm{dq} / \mathrm{dt}=\mathrm{k}_{1}\left(\mathrm{q}_{\mathrm{e}}-\mathrm{q}_{\mathrm{t}}\right)$

Where $\mathrm{k}_{1}\left(\mathrm{~min}^{-1}\right)$ is the rate constant of the pseudo-first-order adsorption, $\mathrm{q}_{\mathrm{t}}(\mathrm{mg} / \mathrm{g})$ denotes the amount of adsorption at time ' $\mathrm{t}$ ' ( $\mathrm{min})$ and $\mathrm{q}_{\mathrm{e}}(\mathrm{mg} / \mathrm{g})$ is the amount of adsorption at equilibrium. The adsorption kinetic data can be further analyzed using pseudo second order kinetics [8]. This is represented by;

$\mathrm{dq} / \mathrm{dt}=\mathrm{k}_{2}\left(\mathrm{q}_{\mathrm{e}}-\mathrm{q}_{\mathrm{t}}\right)^{2}$

Where $\mathrm{q}_{\mathrm{e}}$ and $\mathrm{q}_{\mathrm{t}}$ are the adsorption capacities $(\mathrm{mg} / \mathrm{g})$ at equilibrium and at time ' $\mathrm{t}$ ', respectively; $\mathrm{k}_{1}$ is the rate constant of pseudo-first order adsorption (L/min). The obtained curves by plotting $\log \left(\mathrm{q}_{\mathrm{e}}-\mathrm{q}_{\mathrm{t}}\right)$ versus ' $t$ ' did not show a straight line during the whole adsorption process, indicating that pseudo first order kinetics could not be used to describe the adsorption behavior of indigo carmine dye onto the AC modified metal chlorides.

It is very important to know the rate at which the process takes place and the factors that control the rate of the process, for this purpose kinetics of the process were evaluated. These experiments were conducted for the contact time of 60 to 300 minute by setting initial adsorbent concentration, $\mathrm{pH}$, adsorbent dosage and agitation speed constant. Then sample was withdrawn starting from 60 to 300 minute and in every 60 minute interval for determination of residual dye in the solution. Then data from the experiment was introduced into pseudo-first order model of Lagergren and pseudo second order models. The values of the parameters are given in Table -1 to 3 .

The values of rate constant $\left(\mathrm{k}_{1}\right)$ can be determined from the slope of the linear plot of $\log \left(\mathrm{q}_{\mathrm{e}}\right.$ $q_{t}$ ) versus ' $t$ ' and $k_{2}$ can be calculated from the slope of the linear plot $t / q_{t}$ versus ' $t$ '. The linear plots of two kinetic models are presented in Graph -1 to 6 . The values of $\mathrm{k}_{1}, \mathrm{k}_{2}$ and $\mathrm{q}_{\mathrm{e}}$ and the correlation coefficient $\left(\mathrm{R}^{2}\right)$ from the linear plots are shown in Graph -1 to 6 . The values of correlation coefficient $\left(\mathrm{R}^{2}\right)$ obtained show good correlation. The reason for this behaviour can be attributed to the high competition for the adsorption surface sites at high concentration which leads to lower adsorption rates [9].

The pseudo second order linear plots resulted in higher $\mathrm{R}^{2}$ values than the pseudo first order kinetic model. The values of $\mathrm{q}_{\mathrm{e}}$ (calculated) from the pseudo second order was closer to $\mathrm{q}_{\mathrm{e}}$ (experimental) than that from pseudo first order kinetics. These indicated the better applicability of the pseudo second order model. The pseudo first order linear plots resulted in lesser $\mathrm{R}^{2}$ values than the pseudo second order.

It can be noticed from Graphs, the plots are linear but not passing through the origin and this deviation from the origin or near saturation might be due to the difference in mass transfer rate in the initial and final stages of adsorption [10]. It also indicates that there is an initial boundary layer resistance and intraparticle diffusion is not the sole rate-controlling step, but other kinetic models may simultaneously control the adsorption rate [11].

Table-1: Comparison between Pseudo first order and Pseudo second order kinetic model for removal of Indigo carmine dye on AC modified $\mathbf{F e C l}_{2}$

\begin{tabular}{|c|c|c|c|c|c|c|}
\hline \multicolumn{7}{|c|}{ \% Removal of Indigo carmine dye with $\mathbf{A C}$ modified $\mathbf{F e C l}_{2}\left(\mathrm{q}_{\mathrm{e}}=48.065\right)$} \\
\hline \multicolumn{4}{|c|}{ First order Kinetics } & \multicolumn{3}{|c|}{ Second order Kinetics } \\
\hline Time (t) & $\mathbf{q}_{\mathrm{t}}$ & $\mathbf{q}_{\mathrm{e}}-\mathbf{q}_{\mathrm{t}}$ & $\log \left(q_{e}-q_{t}\right)$ & $\mathbf{t}$ & $\mathbf{q}_{\mathrm{t}}$ & $\mathbf{t} / \mathbf{q}_{\mathrm{t}}$ \\
\hline 60 & 31.835 & 16.23 & 1.210 & 60 & 31.835 & 1.885 \\
\hline 120 & 37.175 & 10.89 & 1.037 & 120 & 37.175 & 3.228 \\
\hline 180 & 40.09 & 7.975 & 0.902 & 180 & 40.09 & 4.489 \\
\hline 240 & 43.455 & 4.61 & 0.664 & 240 & 43.455 & 5.523 \\
\hline 300 & 48.065 & 0 & 0 & 300 & 48.065 & 6.242 \\
\hline
\end{tabular}




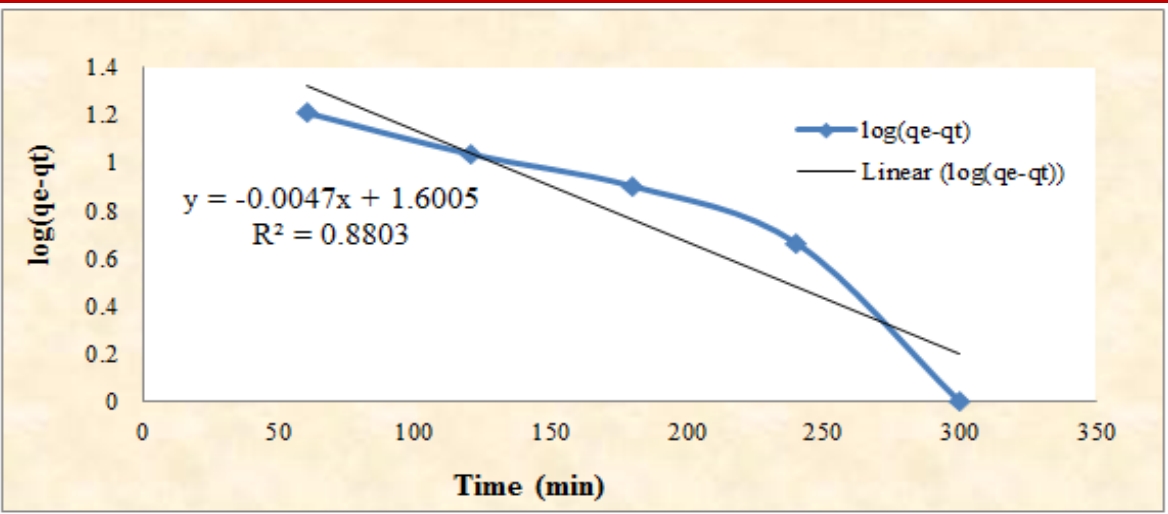

Graph-1: Pseudo-first order ( $\mathrm{AC}$ modified $\mathrm{FeCl}_{2}$ )

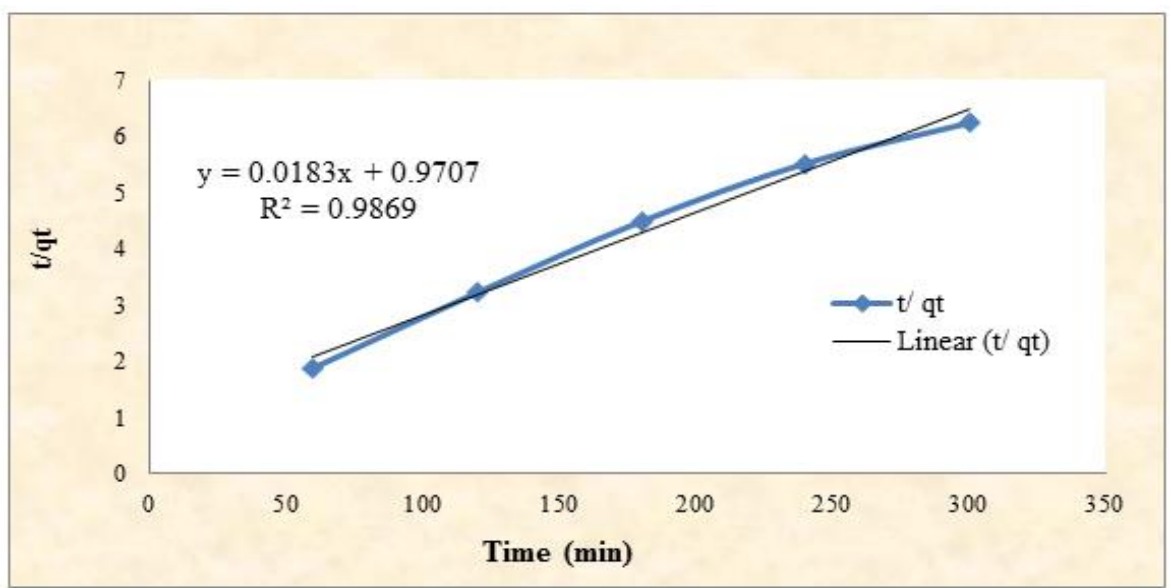

Graph-2: Pseudo-second order ( $\mathrm{AC}$ modified $\mathrm{FeCl}_{2}$ )

Table-2: Comparison between Pseudo first order and Pseudo second order kinetic model for removal of Indigo carmine dye on $\mathbf{A C}$ modified $\mathbf{S r C l}_{2}$

\% Removal of Indigo carmine dye with $\mathbf{A C}$ modified $\mathbf{S r C l}_{2}\left(\mathrm{q}_{\mathrm{e}}=48.575\right)$

\begin{tabular}{|l|l|l|l|l|l|l|}
\hline \multicolumn{5}{|l|}{ First order Kinetics } & \multicolumn{3}{l|}{ Second order Kinetics } \\
\hline Time (t) & $\mathbf{q}_{\mathbf{t}}$ & $\mathbf{q}_{\mathbf{e}}-\mathbf{q}_{\mathbf{t}}$ & $\mathbf{l o g}\left(\mathbf{q}_{\mathbf{e}}-\mathbf{q}_{\mathbf{t}}\right)$ & $\mathbf{t}$ & $\mathbf{q}_{\mathbf{t}}$ & $\mathbf{t} / \mathbf{q}_{\mathbf{t}}$ \\
\hline 60 & 40.88 & 7.695 & 0.886 & 60 & 40.88 & 1.468 \\
\hline 120 & 43.225 & 5.35 & 0.728 & 120 & 43.225 & 2.776 \\
\hline 180 & 45.06 & 3.515 & 0.546 & 180 & 45.06 & 3.995 \\
\hline 240 & 47.025 & 1.55 & 0.190 & 240 & 47.025 & 5.104 \\
\hline 300 & 48.575 & 0 & 0 & 300 & 48.575 & 6.176 \\
\hline
\end{tabular}

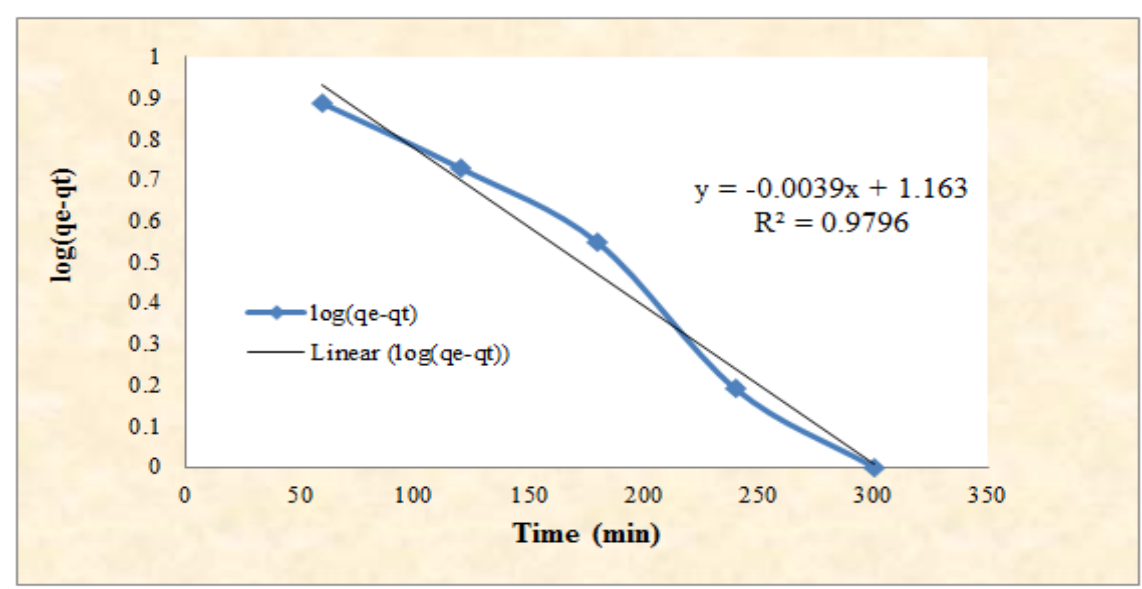

Graph-3: Pseudo-first order (AC modified $\mathrm{SrCl}_{2}$ ) 


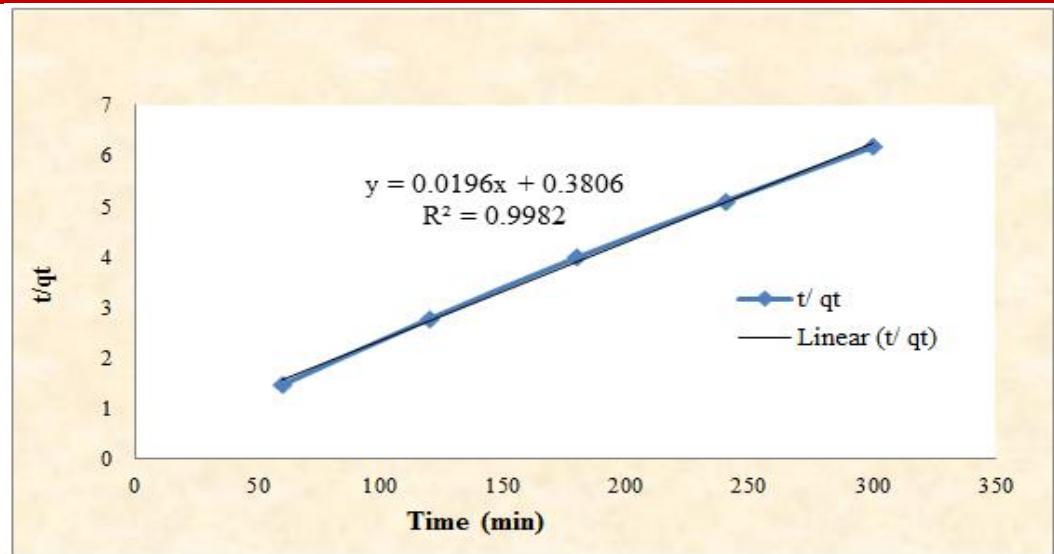

Graph-4: Pseudo-second order (AC modified $\mathrm{SrCl}_{2}$ )

Table-3: Comparison between Pseudo first order and Pseudo second order kinetic model for removal of Indigo carmine dye on $\mathrm{AC}$ modified $\mathrm{BaCl} 2$

\begin{tabular}{|c|c|c|c|c|c|c|}
\hline \multicolumn{7}{|c|}{ \% Removal of Indigo carmine dye with $\mathbf{A C}$ modified $\mathbf{B a C l}_{\mathbf{2}}\left(\mathrm{q}_{\mathrm{e}}=49.902\right)$} \\
\hline \multicolumn{4}{|c|}{ First order Kinetics } & \multicolumn{3}{|c|}{ Second order Kinetics } \\
\hline Time (t) & $\mathbf{q}_{\mathrm{t}}$ & $\mathbf{q}_{\mathrm{e}}-\mathbf{q}_{\mathrm{t}}$ & $\log \left(q_{e}-q_{t}\right)$ & $\mathbf{t}$ & $\mathbf{q}_{\mathrm{t}}$ & $\mathbf{t} / \mathbf{q}_{\mathrm{t}}$ \\
\hline 60 & 41.725 & 8.177 & 0.913 & 60 & 41.725 & 1.438 \\
\hline 120 & 44.23 & 5.672 & 0.754 & 120 & 44.23 & 2.713 \\
\hline 180 & 46.56 & 2.342 & 0.349 & 180 & 46.56 & 3.866 \\
\hline 240 & 48.355 & 1.547 & 0.189 & 240 & 48.355 & 4.963 \\
\hline 300 & 49.902 & 0 & 0 & 300 & 49.902 & 6.012 \\
\hline
\end{tabular}

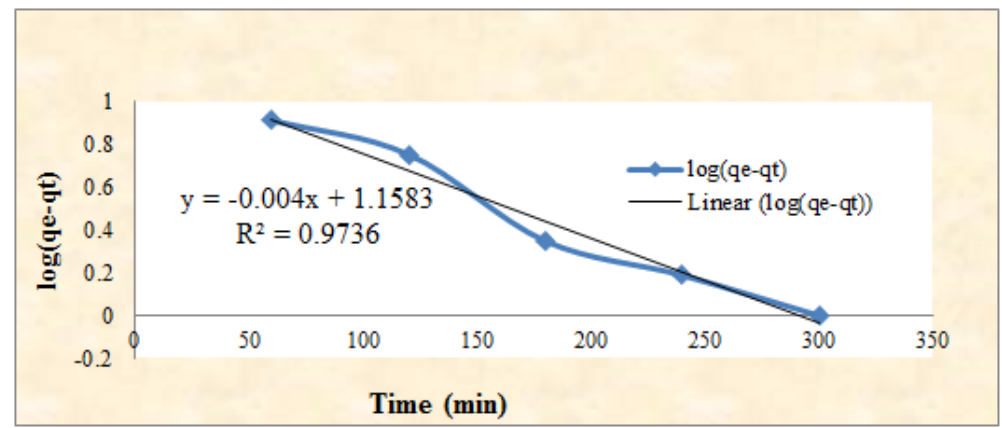

Graph-5: Pseudo-first order (AC modified $\mathrm{BaCl}_{2}$ )

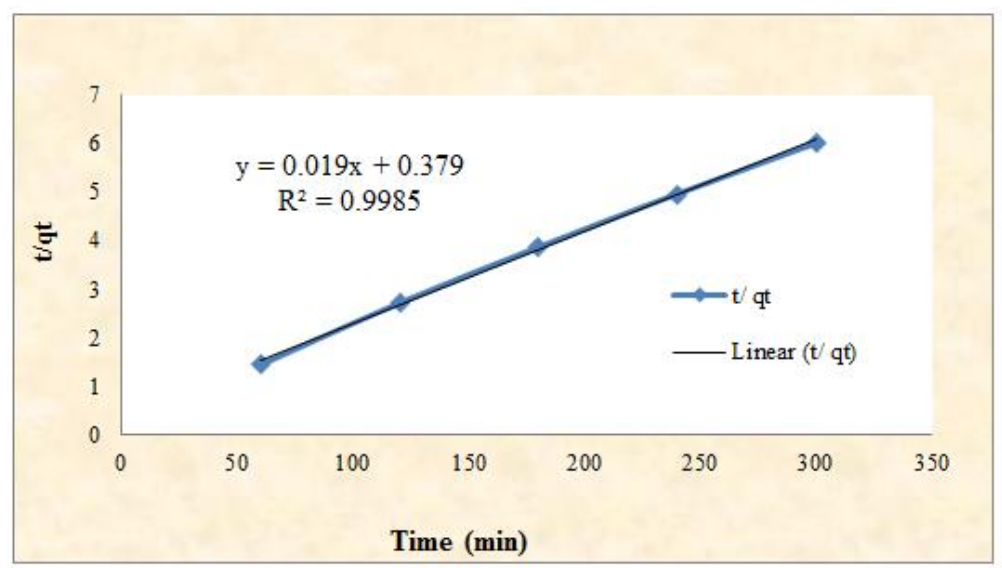

Graph-6: Pseudo-second order ( $\mathrm{AC}$ modified $\mathbf{B a C l}_{2}$ )

The analysis of adsorption process requires a better understanding of adsorption studies. A dynamic equilibrium was established in the concentration of adsorbate between two phases. The equilibrium isotherm is of fundamental importance for the importance for the design and optimization of the 
Sivanthaperumal Pillai \& Thaminum Ansari., Saudi J Med Pharm Sci, Jan, 2022; 8(1): 27-33

adsorption system for the removal of indigo carmine dye from the effluent solution. The initial concentration of dye at $50 \mathrm{ppm} / \mathrm{L}, 100 \mathrm{ppm} / \mathrm{L}, 200 \mathrm{ppm} / \mathrm{L}, 250$ $\mathrm{ppm} / \mathrm{L}$, and $500 \mathrm{ppm} / \mathrm{L}$ and equivalent adsorption in 0.5 $\mathrm{g}$ of sorbent $\left(\mathrm{q}_{\mathrm{e}}\right)$, amount of dye left in solution $\left(\mathrm{C}_{\mathrm{e}}\right)$, and $\mathrm{C}_{\mathrm{e}} / \mathrm{q}_{\mathrm{e}}$ are presented in Table- 4 to 6 .

Table - 4 to 6 showed that the amount of total sorbed dye, equilibrium dye uptake, and total percent removal increased with increasing initial Indigo carmine dye concentration $(\mathrm{mg} / \mathrm{L})$, Equivalent adsorption in $0.5 \mathrm{~g}$ of sorbent $\left(\mathrm{q}_{\mathrm{e}}\right)$, Amount of dye left in solution $\left(\mathrm{C}_{\mathrm{e}}\right)$. The increase in total amount of adsorbed indigo carmine dye $\left(\mathrm{q}_{\mathrm{m}}\right.$ total $)$ and hence percentage removal of Indigo carmine dye was obtained with increasing Indigo carmine dye concentration. These results are in agreement with many investigations for different system. The experimental data were fitted to pseudo-first order and second order adsorption models, because of higher correlation created between dependent and independent variables. Thus hybrid system of adsorption was applied for the removal of indigo carmine dye from combined wastewater of dyes and pigments manufacturing plant was treated with a hybrid process of coagulation and adsorption.

Table-4: Distribution for the adsorbent and adsorbate (Indigo carmine dye with $\mathbf{A C}$ modified $\mathbf{F e} \mathbf{C l}_{2}$ )

\begin{tabular}{|l|l|l|l|l|l|}
\hline Initial Concentration of dye $(\mathbf{p p m} / \mathbf{L})$ & $\mathbf{5 0}$ & $\mathbf{1 0 0}$ & $\mathbf{2 0 0}$ & $\mathbf{2 5 0}$ & $\mathbf{5 0 0}$ \\
\hline Equivalent adsorption in 0.5 g of sorbent $\left(\mathrm{q}_{\mathrm{e}}\right)$ & 47 & 86 & 144 & 165 & 245 \\
\hline Amount of dye left in solution $\left(\mathrm{C}_{\mathrm{e}}\right)$ & 3 & 14 & 56 & 85 & 255 \\
\hline $\mathrm{C}_{\mathrm{e}} / \mathrm{q}_{\mathrm{e}}$ & 0.064 & 0.163 & 0.389 & 0.515 & 1.041 \\
\hline
\end{tabular}

Table-5: Distribution for the adsorbent and adsorbate (Indigo carmine dye with $\mathrm{AC}$ modified $\mathrm{SrCl}_{2}$ )

\begin{tabular}{|l|l|l|l|l|l|}
\hline Initial Concentration of dye $(\mathbf{p p m} / \mathbf{L})$ & $\mathbf{5 0}$ & $\mathbf{1 0 0}$ & $\mathbf{2 0 0}$ & $\mathbf{2 5 0}$ & $\mathbf{5 0 0}$ \\
\hline Equivalent adsorption in $0.5 \mathrm{~g}$ of sorbent $\left(\mathrm{q}_{\mathrm{e}}\right)$ & 45.5 & 82 & 116 & 117.5 & 180 \\
\hline Amount of dye left in solution $\left(\mathrm{C}_{\mathrm{e}}\right)$ & 4.5 & 18 & 84 & 132.5 & 320 \\
\hline $\mathrm{C}_{\mathrm{e}} / \mathrm{q}_{\mathrm{e}}$ & 0.099 & 0.219 & 0.724 & 1.128 & 1.778 \\
\hline
\end{tabular}

Table-6: Distribution for the adsorbent and adsorbate (Indigo carmine dye with $\mathbf{A C}$ modified $\mathbf{B a C l}_{2}$ )

\begin{tabular}{|l|l|l|l|l|l|}
\hline Initial Concentration of dye (ppm/L) & $\mathbf{5 0}$ & $\mathbf{1 0 0}$ & $\mathbf{2 0 0}$ & $\mathbf{2 5 0}$ & $\mathbf{5 0 0}$ \\
\hline Equivalent adsorption in $0.5 \mathrm{~g}$ of sorbent $\left(\mathrm{q}_{\mathrm{e}}\right)$ & 46.5 & 85 & 130 & 145 & 210 \\
\hline Amount of dye left in solution $\left(\mathrm{C}_{\mathrm{e}}\right)$ & 3.5 & 15 & 70 & 105 & 290 \\
\hline $\mathrm{C}_{\mathrm{e}} / \mathrm{q}_{\mathrm{e}}$ & 0.075 & 0.176 & 0.538 & 0.724 & 1.381 \\
\hline
\end{tabular}

It is clear from Graphs (2, 4, and 6), the pseudo first-order model did not adequately fit the experimental data because all values of $\mathrm{R}^{2}$ equal to 0.973. Therefore the pseudo second-order model for adsorption of indigo carmine dye onto activated carbon modified with metal chlorides agree well with experimental data due to all values of $\mathrm{R}^{2}$ are equal to 0.998 .

Also the calculated equilibrium adsorption capacity $\left(\mathrm{q}_{\mathrm{e}}\right.$, calc $)$ for the pseudo first-order model are not close to the experimental values $\left(\mathrm{q}_{\mathrm{e}, \text { exp }}\right)$, for pseudo second-order model the $\left(\mathrm{q}_{\mathrm{e}, \text { calc }}\right)$ values are close to $\left(\mathrm{q}_{\mathrm{e}, \text { exp }}\right)$ for all metal ions. These results can be checked by using the $n$-order equation as below:

$$
\mathrm{dqt} / \mathrm{dt}=\mathrm{k}_{\mathrm{n}} \mathrm{q}_{\mathrm{n}}{ }^{\mathrm{n}}
$$

Integration and applying the boundary conditions $\mathrm{t}=0$ and $\mathrm{q}_{\mathrm{t}}=0$ to $\mathrm{t}=\mathrm{t}$ and $\mathrm{q}_{\mathrm{e}}=\mathrm{q}_{\mathrm{t}}$ the pseudo second-order model (Equ .3) takes the form:

$\ln q_{t} \frac{=\ln \left((1-n) k_{n}\right)}{(1-n)}+\frac{1 \ln t}{(1-n)}$

Applying equ. 4, the values of $\mathrm{n}$ for dye are about 2.2. From these results it can be said that pseudo second-order model is applicable for the adsorption system. The kinetics of adsorption of indigo carmine dye on activated carbon modified metal chlorides were evaluated by pseudo first order kinetics and pseudo second order kinetics.

\section{CONCLUSION}

The adsorption of Indigo carmine dye by Activated carbon modified with $\mathrm{FeCl}_{2}, \mathrm{SrCl}_{2}$, and $\mathrm{BaCl}_{2}$, has been studied. The experimental results indicate that all the metal chlorides adsorbents have higher adsorption capacity for synthetic dyes. The adsorption of Indigo carmine dye over a concentration range 50,100, 200, 250 and $500 \mathrm{ppm}$ were evaluated and decrease in adsorption was observed with increase in initial dye concentration. The optimum conditions of adsorption (adsorbent dose, initial $\mathrm{pH}$, contact time) for the dyes on Activated carbon modified with $\mathrm{FeCl}_{2}$, $\mathrm{SrCl}_{2}$, and $\mathrm{BaCl}_{2}$, were also estimated. The percentage of dyes removal increased corresponding to an increasing the adsorbent dosage up to a maximum level, and there after remained constant. The effect of $\mathrm{pH}$ on the adsorption of dyes on functionalized adsorbent was not significant. 
Sivanthaperumal Pillai \& Thaminum Ansari., Saudi J Med Pharm Sci, Jan, 2022; 8(1): 27-33

The kinetics of adsorption of Indigo carmine dye on activated carbon modified metal chlorides were evaluated by pseudo first order kinetics and pseudo second order kinetics. The pseudo second order model exhibited the best correlation for this experimental result. The results of the present studies indicate that Activated carbon modified with $\mathrm{FeCl}_{2}, \mathrm{SrCl}_{2}$, and $\mathrm{BaCl}_{2}$, can be successfully employed for the removal of Indigo carmine dye over a wide concentration range. Moreover Activated carbon modified with $\mathrm{FeCl}_{2}, \mathrm{SrCl}_{2}$, and $\mathrm{BaCl}_{2}$ have the potential to replace the high cost adsorbents such as activated carbon and thermal activation is an economical method to enhance its adsorption properties. In fact, activated carbon modified metal chlorides show a stronger affinity for dyes due to high adsorption capacity, high surface area and micro porous structure. The study aimed to improve the effectiveness of dyes and pigments wastewater treatment. The experimental data was applied to two kinetic models, pseudo first-order and pseudo secondorder models a comparison between the two models showed that pseudo second order model describe the adsorption process very well and gave best fit with the experimental data with $\mathrm{R}^{2}$ values of 0.998 for indigo carmine dye.

\section{REFERENCES}

1. Lee, J., Mahendra, S., \& Alvarez, P. J. (2010). Nanomaterials in the construction industry: a review of their applications and environmental health and safety considerations. ACS nano, 4(7), 3580-3590.

2. Aslam, M. M., Hassan, I., Malik, M., \& Matin, A. (2004). Removal of copper from industrial effluent by adsorption with economical viable material. Electron. J. Environ. Agric. Food Chem, 3(2), 658-664.

3. Bhatnagar, A., \& Minocha, A. K. (2006). Conventional and non-conventional adsorbents for removal of pollutants from water-A review.
4. Pinotti, A., Bevilacqua, A., \& Zaritzky, N. (1997). Optimization of the flocculation stage in a model system of a food emulsion waste using chitosan as polyelectrolyte. Journal of Food Engineering, 32(1), 69-81.

5. Ahmed, M. K., Das, M., Islam, M. M., Akter, M. S., Islam, S., \& Al-Mansur, M. A. (2011). Physicochemical properties of tannery and textile effluents and surface water of River Buriganga and Karnatoli, Bangladesh. World Applied Sciences Journal, 12(2), 152-159.

6. Aroguz, A. Z., Gulen, J., \& Evers, R. H. (2008). Adsorption of methylene blue from aqueous solution on pyrolyzed petrified sediment. Bioresource Technology,99(6), 15031508 .

7. Rengaraj, S., \& Moon, S. H. (2002). Kinetics of adsorption of Co (II) removal from water and wastewater by ion exchange resins. Water research, 36(7), 1783-1793.

8. Ho, Y. S., \& McKay, G. (1999). A kinetic study of dye sorption by biosorbent waste product pith. Resources, conservation and recycling, 25(34), 171-193.

9. Subbaiah, M. V., Vijaya, Y., Kumar, N. S., Reddy, A. S., \& Krishnaiah, A. (2009). Biosorption of nickel from aqueous solutions by Acacia leucocephala bark: Kinetics and equilibrium studies. Colloids and Surfaces B: Biointerfaces, 74(1), 260-265.

10. Renugadevi, N., Anitha, G., \& Lalitha, P. (2011). Hexavalent chromium removal using a low-cost activated carbon adsorbent from Areca catechu. Indian J. Environ. Prot, 31, 52-58.

11. Krishnan, K. A., Sreejalekshmi, K. G., \& Baiju, R. S. (2011). Nickel (II) adsorption onto biomass based activated carbon obtained from sugarcane bagasse pith. Bioresource technology, 102(22), 10239-10247. 